\title{
Carcinoma de células escamosas em rebordo alveolar inferior: diagnóstico e tratamento odontológico de suporte
}

\section{Squamous cell carcinoma in lower alveolar ridge: diagnosis and odontologic support treatment}

Filipe Ivan Daniel'; Rodrigo Granato ${ }^{2}$; Liliane Janete Grando ; Sônia Maria Lückmann Fabro ${ }^{4}$

\section{unitermos resumo}

Carcinoma epidermóide

Processo alveolar

Tratamento odontológico de

suporte
O carcinoma epidermóide é a neoplasia maligna mais comum de cavidade oral e estruturas adjacentes. Apresenta maior incidência no gênero masculino, após a quarta década de vida, e tem como principais fatores etiológicos os usos crônicos de tabaco e álcool. Neste trabalho é relatado um caso de carcinoma de células escamosas do rebordo alveolar inferior, que não é uma região preferencial para esse tipo de patologia. Também é discutida a importância do cirurgião-dentista na equipe de profissionais que assiste esses pacientes, tanto no diagnóstico precoce quanto no manejo das alterações estomatológicas advindas da terapia antineoplásica.

Squamous cell carcinoma is the most common malignant neoplasm in oral cavity and adjacent structures. Its prevalence is higher in males, after the fourth decade, and the main etiologic associated factors are smoking and alcohol. This study reports a case of squamous cell carcinoma arising from the lower alveolar ridge, a non-preferential site for this pathology. It also discusses the importance of the dentist in the team of professionals assisting these patients, in early diagnosis and treatment of the stomatological alterations due to antineoplastic therapy.

\section{key words}

Squamous cell carcinoma

Alveolar ridge

Dental treatment support

\section{Introdução}

O carcinoma epidermóide, também denominado carcinoma de células escamosas ou carcinoma espinocelular (CEC), representa aproximadamente 90\% das neoplasias malignas da boca e cerca de $38 \%$ dos tumores de cabeça e pescoço $(6,8,19,20)$.

No Brasil, segundo dados do Instituto Nacional do Câncer (INCA)(12), estimou-se que no ano de 2005 ocorreriam em torno de 13 mil novos casos de câncer de cavidade bucal. É considerado o oitavo tumor mais prevalente entre os homens e o nono entre as mulheres.

Cerca de $75 \%$ dos casos de CEC oral ocorrem na faixa etária dos 40 anos, com predomínio do gênero masculino numa relação de $2: 1^{(6,18,19)}$. Entretanto, a incidência dessa patologia em mulheres tem aumentado nos últimos anos, provavelmente pela disseminação entre elas do hábito de fumar ${ }^{(18,20)}$.

Os fatores etiológicos mais comumente associados ao CEC são consumo crônico de tabaco e álcool, exposição

1. Especialista em Radiologia Odontológica e Imaginologia; estagiário do Ambulatório de Estomatologia do Hospital Universitário da Universidade Federal de Santa Catarina (UFSC).

2. Residente em Cirurgia e Traumatologia Bucomaxilofacial do Hospital Universitário da UFSC.

3. Doutora; professora de Patologia Bucal da UFSC e do Ambulatório de Estomatologia do Hospital Universitário da UFSC.

4. Mestre; professora de Patologia Ceral da UFSC e do Ambulatório de Estomatologia do Hospital Universitário da UFSC. 
prolongada à radiação ultravioleta (CEC de lábio), infecções virais (principalmente pelo papilomavírus humano [HPV]), deficiências nutricionais e hereditariedade ${ }^{(5,7,8,16,18,20)}$.

O tabaco e o álcool têm sido apontados como seus principais agentes causadores, pois apresentam efeito sinérgico, agindo, respectivamente, como iniciadores e promotores da carcinogênese $\mathrm{e}^{(19)}$. O risco de indivíduos fumantes desenvolverem CEC oral é proporcional à quantidade e ao tempo de uso do cigarro. Além disso, os efeitos do álcool no organismo resultam da sua propriedade de irritar a mucosa $\mathrm{e}$ da sua capacidade de atuar como solvente de carcinógenos, especialmente os existentes no tabaco ${ }^{(18)}$.

Clinicamente a lesão inicial pode se apresentar como uma alteração leucoplásica ou eritroleucoplásica. Com sua evolução, ocorre crescimento exofítico ou endofítico, de base endurecida e áreas de necrose ${ }^{(8,16)}$. Em casos mais avançados, quando atinge tecido ósseo subjacente, o exame radiográfico poderá mostrar área radiolúcida com margens mal definidas e aspecto de roído de traça(16, 18).

O diagnóstico definitivo deve ser realizado através de exame anatomopatológico, uma vez que pode se confundir com algumas enfermidades de manifestações bucais, como tuberculose, sífilis e paracoccidioidomicose $\mathrm{e}^{(18)}$.

Sob o ponto de vista histopatológico, os tumores bem diferenciados mostram ninhos, colunas e cordões de células oriundas do epitélio pavimentoso; pleomorfismo celular e nucelar; hipercromatismo nuclear; mitoses atípicas em pequeno número; formação de pérolas de ceratina e invasão subepitelial. Nos casos mais indiferenciados, a semelhança com o epitélio pavimentoso é menos acentuada, apresentando menor ceratinização e maior número de mitoses atípicas ${ }^{(16,18,20)}$. É possível também encontrar resposta inflamatória significativa com linfócitos, plasmócitos e macrófagos ${ }^{(18)}$.

Em relação ao prognóstico, vários fatores devem ser considerados: graduação histopatológica e localização anatômica do tumor, idade avançada, estado de saúde geral e do sistema imunológico do paciente ${ }^{(3,6,14,18,19)}$.

A escolha do tipo de tratamento (cirurgia, radioterapia e/ou quimioterapia) está relacionada ao estadiamento clínico e ao grau de diferenciação histopatológico do tumor ${ }^{(3)}$.

\section{Relato de caso}

Paciente com 62 anos de idade, branco, gênero masculino, compareceu ao Ambulatório de Estomatologia do Núcleo de Cirurgia e Traumatologia Bucomaxilofacial e
Patologia Bucal do Hospital Universitário da Universidade Federal de Santa Catarina (UFSC), com queixa de uma bola na boca há aproximadamente oito meses, com dor e ardência. Relatou que dois meses antes, um dente próximo à lesão, com mobilidade aumentada, foi removido por ele próprio. Revelou ser tabagista há 44 anos (uma carteira/dia) e etilista por muitos anos (cessou há quatro anos), além de história de doença pulmonar de origem fúngica há dez anos, com manifestações bucais. Não referiu qualquer alteração sistêmica no momento.

Ao exame clínico, observou-se lesão ulcerada em rebordo alveolar inferior, parte crateriforme e parte vegetante, que se estendia da região do elemento 31 até a região do 36. A lesão apresentava áreas esbranquiçadas e avermelhadas, com base endurecida à palpação e fundo arenoso. A higiene bucal era insatisfatória, com dentição em péssimo estado de conservação e periodontite avançada generalizada (Figura 1).

Foram solicitados exames radiográficos panorâmico, oclusal total de mandíbula e de tórax (perfil e póstero-anterior). A radiografia panorâmica evidenciou extensa área radiolúcida de contornos mal definidos, com aspecto de roído de traça, localizada na região do 36 ao 43, adjacente à lesão clinicamente observada. Na vista oclusal não se observou expansão das corticais alveolares (Figura 1D). As radiografias de tórax mostraram lesões intersticiais pulmonares reticulonodulares com áreas de confluência sugestivas de cicatrizes da infecção fúngica relatada pelo paciente (Figura 2).

As hipóteses diagnósticas sugeridas foram carcinoma espinocelular e úlcera bucal de paracoccidioidomicose. Foi realizada biópsia incisional e o laudo do exame anatomopatológico do fragmento revelou a presença de células com

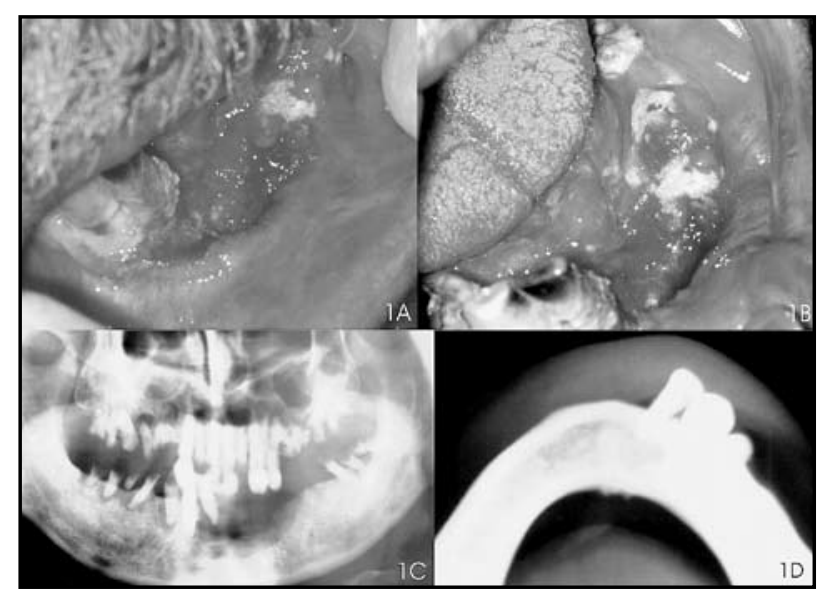

Figura 1 - Exame intra-oral: notar aspecto leucoeritroplásico e presença de úlcera parte crateriforme e parte vegetante (1A e 1B); exame radiográfico: em 1C, imagem radiolúcida de contornos mal-definidos; em 1D, corticais preservadas 


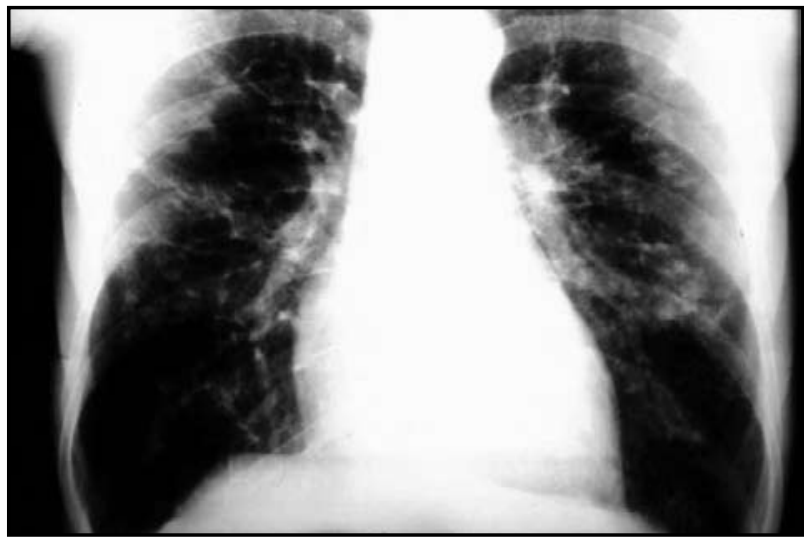

Figura 2 - Radiografia póstero-anterior de tórax: áreas reticulonodulares compatíveis com infecção fúngica prévia (cicatrizes)

citoplasma amplo, eosinofílico, com núcleos pleomórficos, de cromatina irregular, despolarizados, com nucléolos salientes, com focos de ceratinização, infiltração do córion e moderado infiltrado inflamatório mononuclear, compatível com carcinoma espinocelular invasivo e bem diferenciado (Figura 3). O paciente foi encaminhado ao Serviço de Cirurgia de Cabeça e Pescoço do Hospital Universitário, o qual optou por um tratamento não-invasivo à base de radioterapia e quimioterapia.

O paciente retornou ao ambulatório de estomatologia para realização da adequação do meio bucal pré-terapia antineoplásica. Foram realizadas exodontias múltiplas dois meses antes de iniciar a radioterapia e a quimioterapia, principalmente na região que seria irradiada para prevenção de osteorradionecrose (Figura 4). O paciente realizou 35 sessões de radioterapia na região cervicofacial bilateral, com dose total de 7.000cGy e quatro sessões de quimioterapia utilizando a droga cisplatina.

Após esse tratamento, quando retornou para controle ao ambulatório de estomatologia, relatou perda do paladar, boca seca e com ardência, manifestações típicas da fase pósquimioterapia e pós-radioterapia. O paciente foi orientado sobre as seqüelas do tratamento realizado e aconselhado a usar saliva artificial. Os exames clínico e radiográfico de controle revelaram ausência de doença (Figura 5). No momento encontra-se em controle clínico e radiográfico.

\section{Discussão}

O tratamento do câncer de boca pode ser realizado através de cirurgia, radioterapia, ou ambas ${ }^{(18)}$. A radioterapia exclusiva pode ser indicada em pacientes considerados inoperáveis devido à grande extensão do tumor, paliativamente, como no caso relatado ${ }^{(11)}$. A quimioterapia também

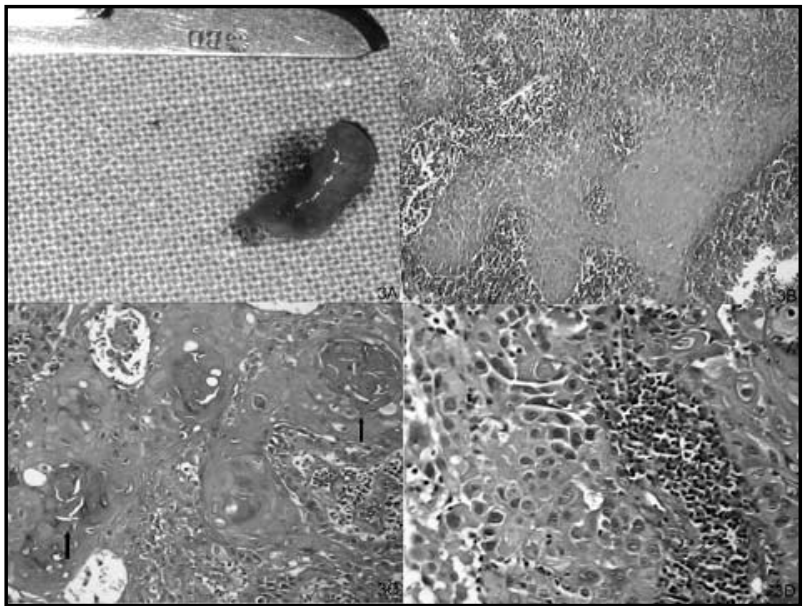

Figura 3 - A: fragmento da lesão removido durante a biópsia; B: exame histopatológico (HE); C: observar presença de pérolas de ceratina (setas); D: detalhe para a alteração da relação núcleo/citoplasma, pleomorfismo celular e mitoses atíicas

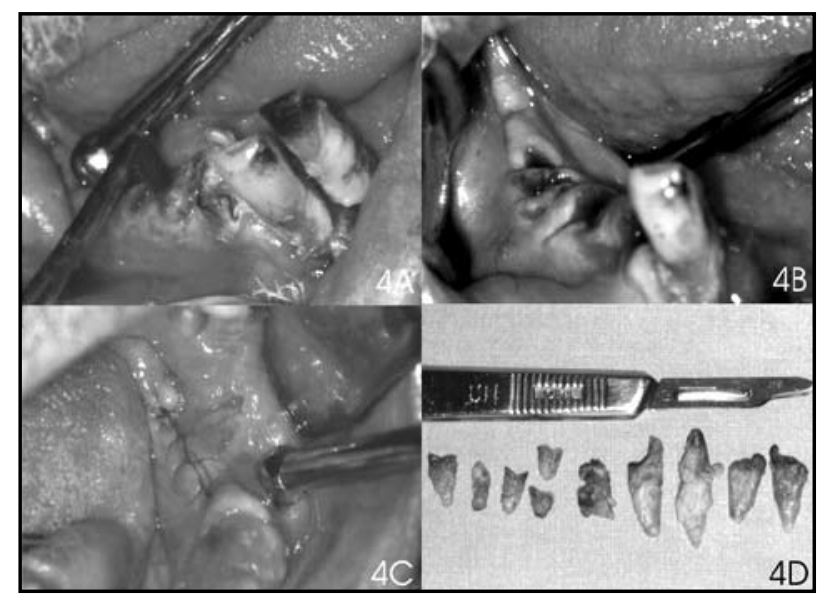

Figura 4 - Preparo pré-terapia antineoplásica: $A, B$ e C: exodontias múltiplas; 5 : fragmentos dentários removidos

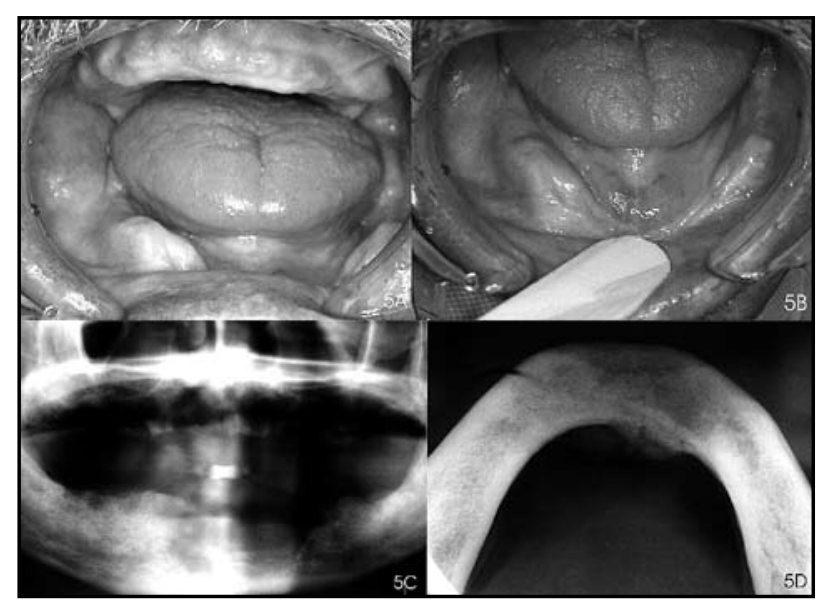

Figura 5 - Exame intrabucal de controle: Notar cicatrização das áreas irradiadas e aspecto de hipossalivação (A e B); exame radiográfico de controle após um ano (C e D) 
pode ser associada como tratamento adjuvante nos casos avançados $^{(18)}$.

Essas duas modalidades terapêuticas (radioterapia e quimioterapia) provocam danos principalmente nas células com alta taxa de divisão. Dessa forma, a mucosa oral normal torna-se alvo primário para a toxicidade em virtude de sua alta taxa de renovação celular. As complicações mais comuns observadas em pacientes irradiados são mucosite, infecção local, dor, hipossalivação, cáries de radiação e osteorradionecrose, que podem levar à dificuldade de alimentação, resultando em desidratação e desnutrição( ${ }^{(15)}$.

Os fatores de risco para desenvolvimento dessas complicações orais durante e após o tratamento são a preexistência de infecções bucais, bem como a falta de cuidados orais adequados. Lesões cariosas, fraturas dentárias, remanescentes radiculares, cálculo dental e doença periodontal contribuem para o desenvolvimento de infecções locais e podem servir de foco para infecções sistêmicas ${ }^{(15)}$.

Uma das principais complicações da terapia antineoplásica e que apresenta tratamento mais difícil é a osteorradionecrose. Os fatores de risco específicos incluem: higiene oral deficiente, infecções dental/periodontal e cirurgias dentoalveolares $(4,9,17)$. No caso descrito havia grande número de elementos dentais com grande destruição coronária e doença periodontal avançada. A estratégia adotada foi a realização de exodontia de todos os remanescentes dentais, como forma de prevenção da osteorradionecrose. Segundo Parise ${ }^{(17)}$, as exodontias devem ser realizadas, sempre que possível, num período mínimo de 14 dias antes do início da irradiação, para permitir a adequada cicatrização da ferida cirúrgica.

Outro efeito colateral observado foi a hipossalivação. As glândulas salivares submetidas à irradiação sofrem um processo de sialadenite pós-radiação(13). $\mathrm{O}$ aumento da ingesta de água e o uso de saliva artificial podem ajudar a controlar esses efeitos, assim como a utilização de drogas estimulantes da produção de saliva, como a pilocarpina ${ }^{(1,2,17)}$.

A perda de paladar pode estar relacionada com danos às papilas gustativas ou às suas fibras nervosas ${ }^{(17,21)}$. Em muitos casos, a sensação é parcialmente restaurada em 20 a 60 dias após a radioterapia e totalmente recuperada dois a quatro meses após ${ }^{(1,2)}$

\section{Conclusão}

O diagnóstico precoce continua sendo o principal fator prognóstico determinante para o tratamento do câncer de boca. Embora nem sempre essa meta seja alcançada, tornase imprescindível a atuação do cirurgião-dentista dentro da equipe multidisciplinar do tratamento antineoplásico, tanto nas fases iniciais de diagnóstico quanto durante a terapia, realizando avaliações estomatológicas e dando condições ao paciente de ser submetido às modalidades terapêuticas com as melhores taxas de cura e de qualidade de vida, prevenindo ou reduzindo os seus efeitos colaterais. A adequação bucal realizada antes de o paciente iniciar a radioterapia e a quimioterapia reduziu a probabilidade de ocorrências das alterações estomatológicas, permitindo melhor qualidade de vida.

\section{Agradecimentos}

À professora Elena Riet Correa Rivero pela digitalização das imagens histopatológicas.

\section{Referências}

I. ANDREWS, N.; GRIFFITHS, C. Dental complications of head and neck radiotherapy: part I. Aust Dent J, v. 46, n. 2, p. 88 94, June 2001.

2.ANDREWS, N.; GRIFFITHS, C. Dental complications of head and neck radiotherapy: part 2. Aust Dent J, v. 46, n. 3, p. $174-182$ Sept 200l.

3. CARVALHO, F. C. R.; DIAS, E. P.; CABRAL, M. G. Fatores prognósticos do câncer bucal. RBO, v. 60, n. I, p. 21-3 2003.

4. CELIK, N. et al. Osteoradionecrosis of the mandible after oromandibular cancer surgery. Plast Reconstr Surg, v. 109, n. 6. p. $|875-8|, 2002$
5. CORRENTI, M. et al. Detection of human papillomaviruses of high oncogenic potential in oral squamous cell carcinoma in a Venezuelan population. Oral Dis, v. 10, n. 3, p. 163-6, 2004

6. COSTA, A. L. L. et al. Correlação entre a classificação TNM, gradação histológica e localização anatômica em carcinoma epidermóide oral. Pesq Odontol Bras, v. 16, n. 3, p. 2 16-20, 2002.

7. DE PETRINI, M. et al. Head and neck squamous cell carcinoma: role of the human papillomavirus in tumour progression. New Microbiol, v. 29, n. I, p. 25-33, 2006.

8. GORLIN, R. J.; GOLDMAN, H. M. Patología oral. Barcelona: Salvat, 1973 
9. HAO, S. et al. Systematic management of osteoradionecrosis in the head and neck. Laryngoscope, v. 109, n. 8, p. 1324-7, 1999.

10. HOWELL, R. E.;WRIGHT,B.A.;DEWAR, R.Trends in the incidence of oral cancer in Nova Scotia from 1983 to 1997. Oral Surg Oral Med Oral Pathol Oral Radiol Endod, v. 95, n. 2, p. 205-12, 2003.

I I. INSTITUTO NACIONAL DO CÂNCER. Carcinoma epidermóide da cabeça e pescoço. Revista Brasileira Cancerologia, v. 47, n. 4, p. 36I-76, 200 I.

12. INSTITUTO NACIONAL DO CÂNCER. Estimativas 2005 - Incidência do câncer no Brasil. Rio de Janeiro, 2004. Disponível em: http://www.inca.gov.br/estimativa/2005/ versaofinal.pdf. Acesso em: 7 maio 2005.

13. LIMA, A. A. S. Avaliação sialométrica e sialoquímica de indivíduos submetidos à radioterapia da região de cabeça e pescoço. Porto Alegre, 1999. Tese (doutorado em Odontologia) Faculdade de Odontologia, Pontifícia Universidade Católica do Rio Grande do Sul.

14. MARTINS, M. N. Sistemas de graduação histopatológica de malignidade (SGHM) do carcinoma espinocelular. Revisão da literatura e sua importância dentro do contexto da estomatologia. Revista Odonto Ciência, n. 28, p. 97-106, 1999.
15. NATIONAL CANCER INSTITUTE. Oral complications of cancer and cancer therapy. Disponível em: http:// cancerweb.ncl.ac.uk/cancernet/302904.html. Acesso em: 20 março 2004.

16. NEVILLE, B.W. et al. Patologia oral e maxilofacial. Rio de Janeiro: Guanabara Koogan, 1998.

17. PARISE, O. Câncer de boca: aspectos básicos e terapêuticos. São Paulo: Sarvier, 2000.

18. REGEZI, J. A.; SCIUBBA, J. J. Patologia bucal: correlações clinicopatológicas. Rio de Janeiro: Guanabara Koogan, 1991.

19. SCHÜTZ, A. B. Carcinoma epidermóide bucal: aspectos microscópicos e comportamento biológico. RGO, v. 45, n. 2, p. 7I-8, 1997.

20. SHAFER,W. G.; HINE, M. K.; LEVY, B. M. Tratado de patologia bucal. 4 ed. Rio de Janeiro: Guanabara Koogan, 1987.

21. TOMMASI, A. F. Diagnóstico em patologia bucal. São Paulo: Pancas, 2002.

22. WISEMAN, S. M. et al. Squamous cell carcinoma of the head and neck in nonsmokers and nondrinkers: an analysis of clinicopathologic characteristics and treatment outcomes. Ann Surg Oncol, v. 10, n. 5, p. 55 I-7, 2003. 